Ihre Fragen zur Abrechnung und zur wirtschaftlichen Praxisführung beantwortet unser Experte Helmut Walbert, Würzburg.

Helmut Walbert

\title{
Schranken für sexuell übergriffige Patienten
}

? Dr. U. P., Allgemeinärztin, Nordrhein: Eine Mitarbeiterin hat mir berichtet, dass ein Patient während der Blutabnahme seine Hand auf ihren Oberschenkel legte und darüber gleiten ließ. Ich bin unsicher, wie ich darauf reagieren soll.

MMW-Experte Walbert: Sie müssen klar und eindeutig reagieren! Für die Mitarbeiter ist die Rolle des Chefs in solchen Situationen von entscheidender Bedeutung. Das Team muss wissen, dass solche Verhaltensweisen nicht toleriert werden. Dazu verpflichtet die Fürsorgepflicht den Arbeitgeber.

In jeder Arztpraxis sollte das Thema vorbeugend in einer Teambesprechung behandelt werden. So können die Mitar- beiter richtig reagieren. In einem Fall wie dem von Ihnen geschilderten muss die Mitarbeiterin sich klar und deutlich äußern dürfen, etwa:

- „Unterlassen Sie diese Berührung!“

- „Halten Sie bitte Abstand!“

- „Ich möchte von Ihnen nicht berührt werden!“

Die Ernsthaftigkeit der Aussage muss durch einen entsprechenden Blick, eine ablehnende Haltung und eine eindeutige Stimmlage unterstrichen werden. Dafür ist natürlich wichtig, dass die Mitarbeiter keinen Zweifel daran haben, dass sie im Einzelfall auf die volle Unterstützung ihrer Chefs vertrauen können. Auf keinen Fall darf die Mitarbeiterin im von Ihnen geschilderten Fall das Gefühl von Peinlichkeit haben oder Unsicher-

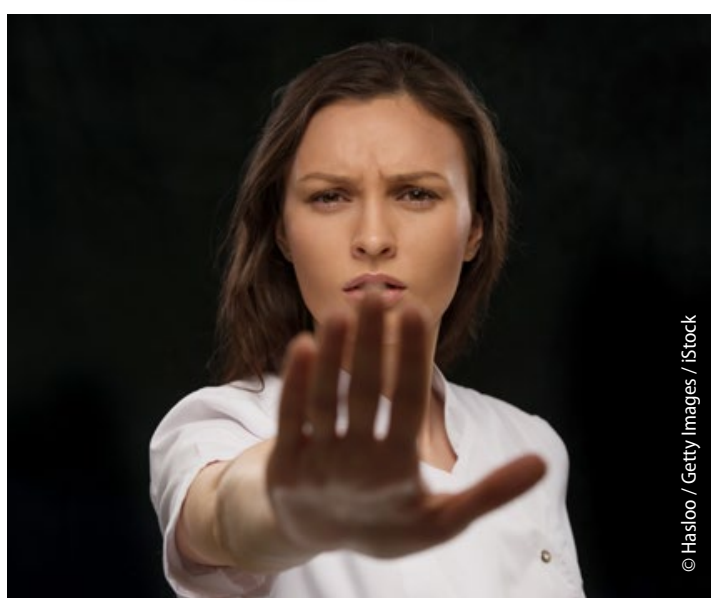

Ermöglichen Sie es Ihren MFA, bei Übergriffen sicher aufzutreten.

heit in der Situation entwickeln. Eine eindeutige Reaktion reicht oft aus, um eine Wiederholung zu vermeiden.

Eines muss im Team klar sein: Sexuelle Belästigung ist kein Kavaliersdelikt. Der Gesetzgeber hat unerwünschtes, sexuell bestimmtes Verhalten, das die Würde der belästigten Person verletzt, unter Strafe gestellt.

\section{Jobsharing mit zusätzlichem Arztsitz}

$?$ Dr. B. Schmedes, Allgemeinärztin, Niedersachsen: Ich habe einen halben Vertragsarztsitz von einem benachbarten Kollegen erworben und diesen als Angestellten in meiner Praxis mit 11 Stunden pro Woche eingestellt. Ende des Monats läuft laut Arbeitsvertrag die Probezeit ab. Die Zusammenarbeit ist unbefriedigend, daher möchte ich mich jetzt von dem Mitarbeiter trennen. Hier stellt sich für mich die Frage, ob ich das darf, und ob ich den erworbenen Kassenarztsitz neu besetzen kann. Ich habe seit gut einem Jahr noch einen Mitarbeiter im Jobsharing. Den würde ich wegen der leidigen Leistungsbegrenzungen auf diesen Sitz einstellen. Gilt hier für mich die Dreijahresfrist, da meine Praxis kein MVZ ist? Im Zulassungsbescheid stehen keine Auflagen. sungsausschuss hat keine Auflagen gemacht. Dies ist die wichtigste Voraussetzung. Eine Beendigung des Angestelltenverhältnisses zum Ende der vereinbarten Probezeit sollte ebenfalls problemlos möglich sein. Der verbleibende halbe Vertragsarztsitz muss innerhalb eines halben Jahres nachbesetzt werden. Das kann wieder ein Assistent sein. Die angedachte Alternative, den Jobsharer auf diese Stelle zu setzen, ist eine wirtschaftlich sinnvolle Lösung, da Jobsharer kein eigenes Budget haben. 